This item was submitted to Loughborough's Research Repository by the author.

Items in Figshare are protected by copyright, with all rights reserved, unless otherwise indicated.

\title{
Parental body dissatisfaction and controlling child feeding practices: A prospective study of Australian parent-child dyads
}

PLEASE CITE THE PUBLISHED VERSION

https://doi.org/10.1016/j.eatbeh.2018.10.002

\section{PUBLISHER}

(C) Elsevier

\section{VERSION}

AM (Accepted Manuscript)

\section{PUBLISHER STATEMENT}

This paper was accepted for publication in the journal Eating Behaviors and the definitive published version is available at https://doi.org/10.1016/j.eatbeh.2018.10.002.

\section{LICENCE}

CC BY-NC-ND 4.0

\section{REPOSITORY RECORD}

Webb, Haley J., and Emma Haycraft. 2018. "Parental Body Dissatisfaction and Controlling Child Feeding Practices: A Prospective Study of Australian Parent-child Dyads”. figshare. https://hdl.handle.net/2134/35444. 
Running Head: Parental controlling feeding practices

Parental Body Dissatisfaction and Controlling Child Feeding Practices: A Prospective Study of Australian Parent-Child Dyads

Haley J. Webb

School of Applied Psychology \& Menzies Health Institute of Queensland,

Griffith University, Gold Coast, Australia

Emma Haycraft

School of Sport, Exercise and Health Sciences,

Loughborough University, United Kingdom

Corresponding Author:

Dr Haley Webb

School of Applied Psychology \& Menzies Health Institute of Queensland

Griffith University,

Gold Coast Australia. 4222

Email: haley.webb@griffithuni.edu.au

Phone: +61 (0)7 56788688

Accepted for publication in: Eating Behaviors | 17 October 2018 


\begin{abstract}
The aim of the present study was to examine whether parents' reported use of controlling feeding practices (restrictive feeding and pressure to eat) change over 6 months, and whether parents' concerns about their own weight and shape are prospectively associated with increasing use of controlling feeding practices. Participants were 48 Australian parents $(92 \%$ female; $M$ age $=37.8$ years $)$ who completed questionnaires twice, with a 6 -month time lag, regarding a target child aged 7.6 years on average ( $52 \%$ female). Results revealed that, in general, parental feeding practices and body dissatisfaction showed little change over 6 months. As expected, parental body dissatisfaction predicted increased use over time of restrictive feeding practices for the purpose of managing child weight, but (unexpectedly) not restrictive feeding for child health or pressure to eat. The findings provide key evidence that parents who use higher levels of controlling feeding practices are likely to continue to do so over time, and that parental body dissatisfaction poses a small but significant risk for parents' increasing use of restrictive feeding for management of child weight. The present findings support suggestions that the connection between parent body dissatisfaction and maladaptive feeding practices play a role in the intergenerational transmission of body image and eating pathology.
\end{abstract}

Keywords: parent, child, controlling feeding practices, restriction, body dissatisfaction, body image, prospective 


\section{Highlights}

- $\quad$ Pressure to eat and restrictive feeding showed rank order consistency over 6 months

- No mean-level differences over time for pressure to eat and restriction for health

- $\quad$ Mean-level differences (i.e., decline) over time found for restriction for weight

- $\quad$ Parent body dissatisfaction predicted greater restrictive feeding for child weight

- $\quad$ Parent body dissatisfaction was not related to pressure or restriction for health 


\section{Parental Body Dissatisfaction and Controlling Child Feeding Practices: A Prospective Study of Australian Parent-Child Dyads}

Parents' use of controlling feeding practices is considered problematic because they have been linked with poorer child eating behaviour and are thought to interfere with children's intrinsic self-regulation of energy intake (Birch, Fisher \& Davison, 2003). With a view to understanding the developmental context in which children's eating behaviours develop, researchers (e.g., Farrow \& Blissett, 2012) have begun to examine the stability and continuity of parental use of controlling feeding practices during childhood. Stability refers to the consistency in individual rank order of behaviour (or individuals' relative placement within a population) over time, and is typically assessed by way of test-retest correlations. Continuity is conceptually and statistically independent from stability (McCall, 1986) and refers to the consistency in the mean level of behaviour over time. Continuity is assessed by examining whether the average level of a particular behaviour differs significantly between two time points (e.g., paired samples $t$-test). Stability of a construct indicates that individuals maintain their relative position within a population over time, whereas continuity of a construct indicates that the population, on average, maintains a consistent level over time. Examining both indices of change is important to provide a more complete developmental picture of risk, and to inform on the need and timing of intervention (McCall, 1986). For example, if controlling feeding practices show inter-individual stability, it would indicate that a particular parent's elevated use of controlling practices at one time point is predictive of their relative risk for ongoing elevated levels. At the same time, it is possible that controlling practices could show a simultaneous mean-level decline (i.e., discontinuity) over time, indicating that while parents may show inter-individual stability, they are also, on average, decreasing in their levels of controlling practices over time, suggestive of declining risk. Both stability and continuity in parents' reported use of controlling feeding practices have been 
explicitly examined during early childhood (i.e., from 2 to 5 years; Farrow \& Blissett, 2012) and across later years of middle childhood (i.e., from 8 to 11 years; Webber, Cooke, Hill, \& Wardle, 2010), however the stability and continuity of parents' reported use of problematic feeding practices in the early years of middle childhood has not been examined. Notably, our focus in the present study was on parents of children in middle childhood, which refers to children around the age of 6 to 11 years. Middle childhood was selected as it is a critical period for the development of children's self-regulation of cognitions and emotions (e.g., Zimmer-Gembeck \& Skinner, 2011), and is characterised by increasing independence (Mah \& Ford-Jones, 2012) including in relation to eating (Haycraft, Farrow, Meyer, Powell, \& Blissett, 2011). As such, middle childhood represents a potentially sensitive period of development during which controlling feeding practices may be particularly problematic, as they might conflict with children's developing autonomy around food and eating.

Researchers have also begun to consider how parents' own eating behaviours and body concerns can be related to the ways in which they feed their children (e.g., Francis et al., 2001), with cross-sectional evidence providing support for a link between parental body dissatisfaction and controlling feeding practices. In a small study that involved observation of mealtime interactions with young children (age 1.5 to 5 years), maternal and paternal eating disorder symptomology, including body dissatisfaction, was examined in relation to observed parental feeding practices (Blissett \& Haycraft, 2011). Body dissatisfaction in mothers and fathers was positively associated with pressure to eat, while body dissatisfaction in mothers was positively associated with restrictive feeding. Moreover, in a sample of mothers with 5year-old daughters, concern about own weight was positively associated with maternal reports of restrictive feeding (Francis et al., 2001). Conversely, in a study of young children (age 1 to 5 years), neither maternal nor paternal body dissatisfaction was associated with feeding practices, with the exception of fathers' body dissatisfaction, which was positively 
associated with monitoring of their sons' eating (Blissett, Meyer, \& Haycraft, 2006). Rodgers and colleagues (2013) similarly found that maternal body dissatisfaction was not associated with restrictive feeding of young children (age 1.5 to 2.5 years). It is notable that Blissett and colleagues (2006) did find that more severe body image and eating disturbances in mothers (i.e., bulimia) were associated with restriction of daughters' eating; a finding replicated in another study of young children (age 1.5 to 5 years; Haycraft \& Blissett, 2008). Taken together, while the evidence is somewhat mixed, there is some indication that body dissatisfaction and more severe body image disturbances are cross-sectionally linked with the use of more controlling feeding practices (and restrictive feeding in particular) in parents of young children.

To our knowledge, only one study (Duke, Bryson, Hammer, \& Agras, 2004) has examined the prospective association of parental (96\% mothers) body dissatisfaction measured at the child's birth, with the use of controlling feeding practices when the child was 7 years old. This study found a positive prospective association between parental body dissatisfaction and pressure to eat (but not restrictive feeding) for sons and daughters. Notably, however, this association was reduced to non-significance when controlling for child BMI, suggesting that parents' concerns about child weight may also be a factor in the association between parental body dissatisfaction and controlling feeding practices.

Researchers have more recently begun to take a more nuanced approach to examining restrictive feeding in light of evidence that parents may restrict their child's diet for multiple reasons or in different ways (Bauer et al., 2017; Musher-Eizenman \& Holub, 2006). The Comprehensive Feeding Practices Questionnaire (CFPQ; Musher-Eizenman \& Holub, 2007) includes subscales to assess restrictive feeding for the purpose of controlling child weight separate from restrictive feeding related to child health, and these subscales have shown a small inter-correlation ( $r=.34$; Musher-Eizenman $\&$ Holub, 2007), and some evidence of 
divergence in associations with children's eating (e.g., Tan \& Holub, 2011). Indeed, it has been suggested that restriction for child health is quite widely accepted, while restriction for child weight may be more culturally influenced (Musher-Eizenman et al., 2009). Notably, none of the studies reviewed above differentiated between restriction for child weight and restriction for child health in association with parent body dissatisfaction. Given the potential relevance of restriction for child weight control, in particular, for mothers with higher body dissatisfaction, the CFPQ was used in the present study to tease out any differences.

Taken together, it remains unclear how parents' use of pressure to eat and restrictive feeding practices may change or show inter-individual stability and mean-level continuity in middle childhood, and whether parents' body dissatisfaction has a proximate and prospective impact on their use of these potentially problematic feeding practices over time. Such findings are pertinent to understanding the developmental context within which children's eating behaviours develop, and have valuable implications for health promotion through illuminating modifiable parental factors as mechanisms to improve child outcomes. Accordingly, the aim of the present study was two-fold. The first aim was to examine the stability and continuity in parents' reported use of controlling feeding practices over 6 months. Building on the existing cross-sectional studies of parents of young children, and the prior prospective study which utilised a 7-year time lag, the second aim of the present study was to examine whether parents' body dissatisfaction is prospectively associated with increasing use of controlling feeding practices (i.e., restrictive feeding and pressure to eat) over 6 months. Our focus in the present study was on parents of children in middle childhood (around age 6 to 11 years). Moreover, the time-lag of 6 months was used to elucidate more proximal effects of parents' body image concerns. The period from pregnancy through the early caregiving years encompasses important periods of transition and change for parents, including for women's body image attitudes (due to the physical and psychological impacts 
of pregnancy), as well as for parental self-concept, relationships, lifestyle and health behaviours, and the shifting of priorities away from oneself and toward one's children (Nelson, 2003; Tiggemann, 2004). Examining the more proximal effect of parental body dissatisfaction during this pivotal developmental period could provide clues as to the potential benefit of intervening at this time, to reduce the risk of increasing use of pressure to eat and restrictive feeding. Finally, parental concern for child weight was assessed and controlled for given evidence of its association with parental feeding practices (Francis et al., 2001).

\section{Method}

\section{Participants}

Participants were 48 Australian parents, who were predominantly female (92\%, $M$ age $=37.8$ years, $S D=7.9)$. Target children about whom parents completed the survey were aged between 6.0 and 9.2 years $(M=7.6, S D=0.8$ years $), 52 \%$ were female, and they were largely described by their parents as being of healthy weight. Parents were predominantly married (69\%), followed by divorced/separated (15\%), living in a de facto relationship (12\%), or single (4\%). Most parents were employed for wages or self-employed (68\%), while a smaller proportion were studying (28\%) or unemployed (4\%). Six percent of parents reported having completed their high school certificate, $25 \%$ completed a certificate, diploma, or advanced diploma, $44 \%$ completed a bachelor or honours degree, and $25 \%$ completed postgraduate training. Parents self-described their cultural background as Australian/English/Anglo-Saxon (79\%), European (8\%), Asian (8\%), or Arabic (2\%). One parent reported being of Aboriginal, Torres Strait Island or South Sea Island descent.

\section{Procedure}

Study approval was obtained from the university Human Research Ethics Committee. Parents with a child aged 6 to 9 years were recruited through Facebook and via staff and 
student networks at a university in Southeast Queensland, Australia. Parents and children completed measures at two time points ( $\mathrm{T} 1$ and $\mathrm{T} 2$ ), six months apart. At $\mathrm{T} 1$ and $\mathrm{T} 2$, parents completed a 40-minute survey either electronically or via paper and pencil. Children completed behavioural tasks to assess executive functioning at the university at T1 taking about an hour, and a 5-minute survey electronically at T1 and T2 (child measures are not included in the present study). Parents were compensated with a $\$ 50$ gift card at $\mathrm{T} 1$, and a \$20 gift card at T2. Small gifts, such as novelty erasers and stickers, were given to children at both time points. The small sample size in this study $(N=48)$ was due to the demands placed on families to attend the university and complete behavioural assessments. However, power analyses determined that this sample size was sufficient to detect moderate strength effects $(r$ $=.35)$ with $80 \%$ power.

Body dissatisfaction. Parental body dissatisfaction was assessed using the Figure Rating Scale (Stunkard, Sorenson, \& Schulsinger, 1983). Parents were presented with nine gender-specific figures of increasing size, each designated with a numerical rating. Parents indicated the figure that they felt best reflected their current body size and their ideal body size, with the discrepancy between the two ratings taken to indicate degree of body dissatisfaction. The Figure Rating Scale has demonstrated good test-retest reliability and moderate convergence with other measures of body image (Thompson \& Altabe, 1991).

Controlling child feeding practices. Controlling child feeding practices were assessed using three subscales from the Comprehensive Feeding Practices Questionnaire (CFPQ; Musher-Eizenman \& Holub, 2007): pressure to eat (4 items; e.g., "My child should always eat all of the food on his/her plate"), restriction for health (4 items; e.g., "If I did not guide or regulate my child's eating, s/he would eat too much of his/her favourite foods"), and restriction for weight control (8 items; e.g., “There are certain foods my child shouldn't eat because they will make him/her fat"). Responses ranged from 1 (disagree) to 5 (agree). Items 
were averaged to create subscale scores, with higher scores indicating more controlling feeding practices. Cronbach's $\alpha$ in the present study were $.74, .77$, and .87 , respectively. The validity of the CFPQ is supported by convergent associations with measures of parental feeding attitudes and concerns (Musher-Eizenman \& Holub, 2007), and validation among diverse cultural groups (Al-Qerem, Ling, \& Bawab, 2017).

Concern about child eating and weight. The 3 -item concern about child weight subscale of the Child Feeding Questionnaire (CFQ; Birch et al., 2001) was used to assess parental concern about child eating and weight. An example item is: "How concerned are you about your child becoming overweight?" $(1$ = unconcerned, 5 = very concerned $)$. Items are averaged to form a total score, with a higher score indicating greater concern about child weight. Cronbach's $\alpha$ in the present study was .94 . The CFQ has been validated for use in culturally diverse samples (e.g., Geng et al., 2009), and the validity of the concern about child weight subscale is supported by positive associations with objectively measured child weightfor-height (Birch et al., 2001).

\section{Overview of the Data Analyses}

One parent had missing data for some items on the CFPQ at T1, and so average scores were formed on the basis of remaining items. Means $(M \mathrm{~s})$ and standard deviations (SDs) of all variables were calculated. Next, Pearson correlations (two-tailed tests of significance) and paired samples $t$-tests between T1 and T2 parental controlling feeding practices and body dissatisfaction were calculated, to examine the inter-individual stability and mean-level continuity of these variables. Finally, a series of multiple regression analyses was conducted to evaluate whether parental body dissatisfaction at $\mathrm{T} 1$ prospectively predicts parental controlling feeding practices at T2 (three models: parental pressure to eat, restriction for child health, and restriction for child weight). Parental controlling feeding practices and parental concern for child weight at $\mathrm{T} 1$ were included in regression models as covariates. 


\section{Results}

Table 1 presents the $M$ s and $S D$ s for all variables, and prospective correlations and paired samples $t$-tests between T1 and T2 controlling feeding practices and body dissatisfaction. The covariate, parental concern about child weight at T1, was found to be significantly associated with T1 and T2 parental restriction for child health $(r=.54 ; r=43)$ and for child weight $(r=.68 ; r=59)$, but was not significantly associated with T1 and T2 pressure to eat $(r=-.11 ; r=-.04)$ or maternal body dissatisfaction $(r=.23 ; r=.08)$.

Stability of controlling feeding practices. Parents' reported use of pressure to eat ( $r$ $=.76)$, restriction for health $(r=.58)$, and parents' body dissatisfaction $(r=.78)$ showed strong stability over 6 months, while restriction for weight showed moderate stability $(r=$ .40). In other words, parents maintained their relative position on each of these measures over time.

Continuity of controlling feeding practices. Parents' reported use of pressure to eat $(t[47]=1.29, p=.20)$ and restriction for health $(t[47]=1.89, p=.07)$, and body dissatisfaction $(t[47]=-0.46, p=.65)$ showed continuity over 6 months, while restriction for weight showed discontinuity in the form of decline over time $(t[47]=-5.80, p<.001)$. That is, the average level of parental pressure to eat, restriction for health, and body dissatisfaction did not significantly differ between $\mathrm{T} 1$ and $\mathrm{T} 2$, whereas restriction for weight declined over time.

\section{Regressing Parental Controlling Feeding Practices on Body Dissatisfaction}

Parental restriction for child health. Table 2 presents results of the multiple regression analyses. The model regressing parental restriction for child health at $\mathrm{T} 2$ from parental body dissatisfaction, controlling feeding practices, and concern about child weight at T1 was found to be significant, $F(5,42)=5.27, p=.001, R_{\text {adj }}^{2}=.31$. Only parental restriction 
for child health at T1 was found to be uniquely and positively associated with parental restriction for child health at $\mathrm{T} 2(\beta=.50, p=.001)$.

Parental restriction for child weight. The model regressing parental restriction for child weight at T2 from parental body dissatisfaction, controlling feeding practices, and concern about child weight at T1 was found to be significant, $F(5,42)=23.18, p<.002, R^{2}$ adj $=.70$. Parental body dissatisfaction $(\beta=.19, p=.03)$ and restriction for child weight $(\beta=.83$, $p<.001)$ at T1 were found to be uniquely and positively associated with parental restriction for child weight at $\mathrm{T} 2$.

Parental pressure to eat. The model regressing parental pressure to eat at $\mathrm{T} 2$ from parental body dissatisfaction, controlling feeding practices, and concern about child weight at T1 was found to be significant, $F(5,42)=12.15, p<.001, R^{2}$ adj $=.54$. Only parental pressure at T1 was found to be uniquely and positively associated with parental pressure at $\mathrm{T} 2(\beta=$ $.77, p<.001)$.

\section{Discussion}

The aim of the present study was to examine the inter-individual stability and meanlevel continuity in parents' reported use of pressure to eat and restrictive feeding practices over 6 months, and to determine whether parental body dissatisfaction was predictive of increasing use of these practices over 6 months. The target age group included parents of children in the early years of middle childhood, given suggestions that children tend to show increasingly internalised regulation of thoughts, feelings and behaviours at this time, and greater autonomy over eating (Haycraft et al., 2011; Mah \& Ford-Jones, 2012). Interindividual stability in parental pressure to eat and restrictive feeding, as well as parental body dissatisfaction, was demonstrated over 6 months, while mean-level continuity was found for parental pressure to eat, restriction for health and body dissatisfaction, but not restriction for weight. As expected, parental body dissatisfaction predicted increased use of restrictive 
feeding practices for the purpose of managing child weight, but (unexpectedly) not restrictive feeding for child health or pressure to eat.

\section{Stability and Continuity of Parental Controlling Feeding Practices}

The results of the present study contribute to a broader picture of the inter-individual stability and mean-level continuity of parents' reported use of controlling feeding practices across childhood. Drawing on evidence of stability among parents of children in early childhood (Farrow \& Blissett, 2012) and later childhood (Webber et al., 2010), in conjunction with the present results suggesting stability in middle childhood, we conclude that parents tend to report stability in their use of restrictive feeding and pressure to eat across the childhood years. This is corroborated by another study focused on middle childhood $\left(M_{\mathrm{age}}=\right.$ 8.7 years), which showed that children also reported stability in their perceptions of their parents' use of pressure to eat and restrictive feeding over 12 months (Houldcroft, Farrow, \& Haycraft, 2016). Taken together, this evidence of inter-individual stability suggests that a parent who scores higher than their peers on pressure to eat and restrictive feeding practices will tend to remain higher as their child grows, and a parent who scores lower will tend to remain lower.

In contrast to stability (i.e., consistency in individual rank-order over time) which has been reliably demonstrated in parental pressure to eat and restrictive feeding, continuity (i.e., consistency in mean-level over time) of parental controlling feeding practices is less clearcut. First, the present study demonstrated mean-level continuity over 6 months during the early years of middle childhood (i.e., from an average age of 7 years) in parental pressure to eat, restriction for health and body dissatisfaction, while restriction for weight was found to decline (i.e., showed discontinuity). It may be that during this developmental period characterised by a slowing of children's physical growth, emerging body image concerns, and internalised regulation of thoughts and behaviour (Hoffnung, 2016; Mah \& Ford-Jones, 2012; 
Ricciardelli \& McCabe, 2001), parents might, on average, reduce their restrictive feeding practices pertaining to child weight management, but maintain similar levels of controlling feeding practices that relate to their child's health more broadly (i.e., pressure to eat, restriction for child health). Among parents of young children, Farrow and Blissett (2012) previously found continuity in parents' reported use of restrictive feeding and monitoring of child eating, but a significant increase in pressure to eat between child age 2 and 5 years. On the other hand, across the later years of middle childhood (from child age 8-11 years), Webber and colleagues (2010) found parental pressure to eat, restrictive feeding, and monitoring of child eating to be discontinuous, whereby parents reported a significant decline in all controlling feeding practices. These findings may indicate that in early childhood when many children show rising food fussiness (Taylor, Wernimont, Northstone, \& Emmett, 2015), parents may increase in their use of pressure to eat, but show continuity of restrictive feeding. As children establish more autonomy across early-late middle childhood, and show more internalised self-regulation of thoughts and behaviour, parents on average demonstrate a decline (i.e., discontinuity) in their controlling feeding practices, relinquishing restriction for weight management prior to restriction for health and pressure to eat. Longitudinal research that spans early to later childhood will enable verification of these findings and clearer developmental tracking of parental feeding practices.

\section{Parental Body Dissatisfaction and Controlling Feeding Practices}

Our notable finding that parental body dissatisfaction was a significant predictor of increasing use of restrictive feeding for managing child weight aligns with previous research evidence of mothers' more severe body image and eating pathology, in the form of bulimic symptomology, being concurrently linked with greater use of restrictive feeding practices with young children (Blissett et al., 2006; Haycraft \& Blissett, 2008). The present findings extend on this existing evidence by showing the prospective impact of parents' body 
dissatisfaction, even over a relatively short period of time, on restrictive feeding during middle childhood. Increasing use of such controlling feeding practices during this developmental stage is concerning, as it reflects the age at which children are taking on increasing autonomy around food intake, and children begin to experience body image concerns (Haycraft et al., 2011; Ricciardelli \& McCabe, 2001).

The one existing prospective study that has examined the role of parental body dissatisfaction on controlling feeding practices similarly investigated feeding during middle childhood. This study (Duke et al., 2004) found that parental body dissatisfaction around child birth was positively associated with use of pressure to eat 7 years later (i.e., at child age 7). Together with the findings of the present study, which found a prospective association with restrictive feeding for child weight, this suggests that parents' body image attitudes around child birth, as well as during children's formative years, may prime a parent to be more attentive to their child's eating and weight, and make them vulnerable to the use of more controlling feeding practices. While the target of pressuring practices and restrictive practices have inverse intents (i.e., for a child to eat more versus to eat less), these controlling practices likely share a common motivation to improve the balance of healthy and unhealthy food intake (Shloim, Edelson, Martin, \& Hetherington, 2015). These findings are critical as they highlight both the enduring and the more proximal impacts of parental body dissatisfaction on the use of controlling feeding practices. These findings also suggest that it is never too early to intervene to support parents in establishing healthy body image attitudes and feeding practices, and also that remediation for parental body dissatisfaction once feeding practices are already well-established and stable may also confer benefits to parent-child interactions around feeding, and in turn, child eating and weight outcomes (Faith, Scanlon, Birch, Francis, \& Sherry, 2004). 
It is notable that the prospective association between parent body dissatisfaction and pressure to eat found by Duke and colleagues (2004) was reduced to non-significance when controlling for child BMI. In the present study, the children were predominantly of healthy weight, and the association between parent body dissatisfaction and restrictive feeding for child weight remained even when controlling for a related variable - parental concern about child weight (which is positively associated with objective measures of child weight; Birch et al, 2001). Together, these findings are consistent with suggestions that parents' use of feeding practices are responsive to child characteristics, such as children's weight (Jansen et al., 2014), but that they are also influenced by parental attitudes and psychological symptomology (e.g., Blissett \& Farrow, 2007). The present findings in particular emphasise that even among a sample of predominantly healthy weight children, elevated parent body dissatisfaction poses a risk for the increasing use of restriction for the purpose of managing child weight, even when controlling for parental concern about child weight.

It is important to note that while some studies found parental body dissatisfaction to be linked with greater pressure to eat but not restrictive feeding (e.g., Duke et al., 2004), others found body dissatisfaction to be associated with greater restrictive feeding practices but not pressure to eat (e.g., Francis et al., 2001). As such, there is a lack of consistency in terms of which specific controlling feeding practices are linked with elevated parental body dissatisfaction. However, as mentioned previously, it may be that these practices employ differing strategies (i.e., increase versus decrease intake) to achieve a common goal of improving the balance of healthy and unhealthy food intake (Shloim et al., 2015). On the other hand, a number of cross-sectional studies have failed to find any association between parental body dissatisfaction and use of controlling feeding practices (e.g., Rodgers et al., 2013; Tiggemann \& Lowes, 2002), while those studies that did find a significant correlation, including the present study, tended to show only a small to moderate association (e.g., 
Blissett \& Haycraft, 2011; Blissett et al., 2006). To assess parent body dissatisfaction most previous studies used the Eating Disorder Inventory-2 (e.g., Blissett \& Haycraft, 2011; Blissett et al., 2006), with fewer studies using a figure rating scale (e.g., present study; Tiggemann \& Lowes, 2002). This methodological difference could potentially account for some of the differences found between the results of our study and others. Moreover, the inconsistencies in the literature likely reflect a more complicated reality than what is currently depicted. For example, parental body image disturbances may pose an elevated risk for the excessive use of particular controlling feeding practices for some parents and children but not others, such as parents and children who are overweight (in reference to restrictive feeding) or underweight (in reference to pressured feeding). Indeed, one cross-sectional study of parents' restrictive feeding (child age range $=7-17$ years) found a significant interaction of parental weight with parental body dissatisfaction (Gray, Janicke, Wistedt, \& DumontDriscoll, 2010). Specifically, higher parental weight was associated with more restrictive feeding practices, and this association was exacerbated among parents with higher compared to lower body dissatisfaction. In addition, there may be distinct correlates and consequences of feeding practices that have different aims or motivations. For example, as was found in the present study, predictors and outcomes may differ for restrictive practices enacted for the purpose of managing child weight compared to restrictive practices for managing child health. These findings highlight the continued need for more nuanced examinations, including appropriately comprehensive assessment of feeding practices, and the potential moderation of the association between parental body dissatisfaction and controlling feeding practices by particular parent and child characteristics, such as parent and child weight (e.g., Gray et al., 2010) and gender (e.g., Blissett \& Haycraft, 2011).

\section{Limitations, Future Directions and Conclusions}


Previous research suggests that the use of certain controlling feeding practices may differ between particular socio-cultural groups. For example, pressure to eat has been found to be more elevated among families with lower income (Wehrly, Bonilla, Perez, \& Liew, 2014), and restrictive feeding practices were shown to be more prevalent in French compared to American parents (all predominantly Caucasian; Musher-Eizenman, de Lauzon-Guillain, Holub, Leporc, \& Charles, 2009), and in Asian American parents compared to White Hispanic and Non-Hispanic American parents (Wehrly et al., 2014). It is important to note, therefore, that the present prospective study is limited by a small sample of predominantly Caucasian Australian parents, which lacked diversity in cultural background and ethnicity, family structure, parent gender, and perceived child weight status. This poses limitations to the generalisability of our findings, as well as statistical power and ability to conduct more sensitive analyses (e.g., moderation by parental or child weight and gender). Moreover, as is the case of much of the existing research (for exceptions see Blissett \& Haycraft, 2011; Farrow, Haycraft, \& Blissett, 2015), measures used in the present study were reliant on parent self-report. Finally, each of the restrictive feeding scales contained at least one item that did not explicitly name health or weight as a motivation for restriction (see Musher-Eizenman \& Holub, 2007). Therefore, while internal consistency of each scale was adequate, and most items were explicit, these measures may not be a perfect representation of restriction for child health versus child weight.

Going forward, prospective and experimental research that captures the attitudes, concerns and feeding practices of a more representative sample of parents, and utilising multi-method assessment approaches including observation of mealtimes, is therefore required. In addition, as mentioned above, further analysis of the conditions under which parental body image attitudes lead to increasing use of particular maladaptive feeding practices, including pressured feeding, and restrictive feeding for child weight versus child 
health, will enable a more complete picture of the risk posed by parental attitudes within the feeding domain.

In summary, the present prospective research contributes to our understanding of the inter-individual stability of parents' reported use of controlling feeding practices across childhood, whereby parents who score higher on such practices are likely to remain higher over time. Viewing the present findings alongside the existing literature, it also appears that parents, on average, show periods of continuity and discontinuity in their use of controlling feeding practices that align with typical developmental changes in children's eating behaviour (such as changes in children's food fussiness and eating self-regulation). In addition, the present research provides key evidence that parental body dissatisfaction poses a small but significant risk for parents' increasing use of restrictive feeding for the purpose of managing child weight. This finding was evident over a relatively short period of time (i.e., 6 months), and during a crucial developmental period where children establish increasing autonomy around eating. As a result, these findings provide prospective evidence for suggestions that linkages between parent body dissatisfaction and maladaptive feeding practices play a role in the intergenerational transmission of body image and eating pathology (Tiggemann \& Lowes, 2002). 


\section{References}

Al-Qerem, W. A., Ling, J., \& Al Bawab, A. (2017). Validation of the comprehensive feeding practice questionnaire among school aged children in jordan: A factor analysis study. International Journal of Behavioral Nutrition and Physical Activity, 14(1), 23. doi:10.1186/s12966-017-0478-y

Bauer, K., Haines, J., Miller, A., Rosenblum, K., Appugliese, D., Lumeng, J., \& Kaciroti, N. (2017). Maternal restrictive feeding and eating in the absence of hunger among toddlers: A cohort study. International Journal of Behavioral Nutrition and Physical Activity, 14(1), 172. doi:10.1186/s12966-017-0630-8

Birch, L. L., Fisher, J. O., \& Davison, K. K. (2003). Learning to overeat: Maternal use of restrictive feeding practices promotes girls' eating in the absence of hunger. American Journal of Clinical Nutrition, 78, 215-220.

Birch, L. L., Fisher, J. O., Grimm-Thomas, K., Markey, C. N., Sawyer, R., \& Johnson, S. L. (2001). Confirmatory factor analysis of the child feeding questionnaire: A measure of parental attitudes, beliefs and practices about child feeding and obesity proneness. Appetite, 36(3), 201-210. doi:10.1006/appe.2001.0398

Blissett, J., \& Farrow, C. (2007). Predictors of maternal control of feeding at 1 and 2 years of age. International Journal of Obesity, 31(10), 1520-1526. doi:10.1038/sj.ijo.0803661

Blissett, J., \& Haycraft, E. (2011). Parental eating disorder symptoms and observations of mealtime interactions with children. Journal of Psychosomatic Research, 70(4), 368371. doi:10.1016/j.jpsychores.2010.07.006

Blissett, J., Meyer, C., \& Haycraft, E. (2006). Maternal and paternal controlling feeding practices with male and female children. Appetite, 47(2), 212-219. doi:10.1016/j.appet.2006.04.002 
Dietz, W. H. (1994). Critical periods in childhood for the development of obesity. American Journal of Clinical Nutrition, 59, 955-959. doi:10.1093/ajen/59.5.955

Duke, R. E., Bryson, S., Hammer, L. D., \& Agras, W. S. (2004). The relationship between parental factors at infancy and parent-reported control over children's eating at age 7. Appetite, 43(3), 247-252. doi:10.1016/j.appet.2004.05.006

Faith, M. S., Scanlon, K. S., Birch, L. L., Francis, L. A., \& Sherry, B. (2004). Parent-child feeding strategies and their relationships to child eating and weight status. Obesity Research, 12(11), 1711-1722. doi:10.1038/oby.2004.212

Farrow, C., \& Blissett, J. (2012). Stability and continuity of parentally reported child eating behaviours and feeding practices from 2 to 5 years of age. Appetite, 58(1), 151-156. doi:10.1016/j.appet.2011.09.005

Farrow, C., Haycraft, E., \& Blissett, J. (2015). Teaching our children when to eat: How parental feeding practices inform the development of emotional eating-a longitudinal experimental design. American Journal of Clinical Nutrition, 101(5), 908-913. 10.3945/ajcn.114.103713

Francis, L. A., Hofer, S. M., \& Birch, L. L. (2001). Predictors of maternal child-feeding style: Maternal and child characteristics. Appetite, 37, 231-243. doi:10.1006/appe.2001.0427

Geng, G., Zhu, Z., Suzuki, K., Tanaka, T., Ando, D., Sato, M., \& Yamagata, Z. (2009). Confirmatory factor analysis of the child feeding questionnaire (CFQ) in Japanese elementary school children. Appetite, 52(1), 8-14. doi:10.1016/j.appet.2008.06.015

Gray, W. N., Janicke, D. M., Wistedt, K. M., \& Dumont-Driscoll, M. C. (2010). Factors associated with parental use of restrictive feeding practices to control their children's food intake. Appetite, 55(2), 332-337. 10.1016/j.appet.2010.07.005 
Haycraft, E., \& Blissett, J. (2008). Controlling feeding practices and psychopathology in a non-clinical sample of mothers and fathers. Eating Behaviors, 9(4), 484-492. doi:10.1016/j.eatbeh.2008.07.007

Haycraft, E., Farrow, C., Meyer, C., Powell, F., \& Blissett, J. (2011). Relationships between temperament and eating behaviours in young children. Appetite, 56(3), 689-692. 10.1016/j.appet.2011.02.005

Houldcroft, L., Farrow, C., \& Haycraft, E. (2016). Eating behaviours of preadolescent children over time: Stability, continuity and the moderating role of perceived parental feeding practices. International Journal of Environmental Research and Public Health, 13(4), 437. doi:10.3390/ijerph13040437

Jansen, P. W., Tharner, A., Van Der Ende, J., Wake, M., Raat, H., Hofman, A., . . Tiemeier, H. (2014). Feeding practices and child weight: Is the association bidirectional in preschool children? American Journal of Clinical Nutrition, 100(5), 1329-1336. doi:10.3945/ajen.114.088922

Johnson, S. L., \& Birch, L. L. (1994). Parents' and children's adiposity and eating style. Pediatrics, 94.

Mah, K. V., \& Ford-Jones, L. E. (2012). Spotlight on middle childhood: Rejuvenating the 'forgotten years'. Paediatrics and Child Health, 17(2), 81-83. doi:10.1093/pch/17.2.81

McCall, R. B. (1986). Issues of stability and continuity in temperament research. In R. Plomin, J. Dunn (Eds.), The study of temperament: Changes, continuities, and challenges (pp. 13-25). New Jersey: Lawrence Erlbaum Associates, Inc.

Musher-Eizenman, D. R., de Lauzon-Guillain, B., Holub, S. C., Leporc, E., \& Charles, M. A. (2009). Child and parent characteristics related to parental feeding practices. A crosscultural examination in the US and France. Appetite, 52(1), 89-95. doi:10.1016/j.appet.2008.08.007 
Musher-Eizenman, D., \& Holub, S. (2006). Children's eating in the absence of hunger: The role of restrictive feeding practices. In Childhood Obesity: New Research, Hauppauge, NY (pg. 135-156).

Musher-Eizenman, D., \& Holub, S. (2007). Comprehensive feeding practices questionnaire: Validation of a new measure of parental feeding practices. Journal of Pediatric Psychology, 32(8), 960-972. doi:10.1093/jpepsy/jsm037

Nelson, A. M. (2003). Transition to motherhood. Journal of Obstetric, Gynecologic \& Neonatal Nursing, 32(4), 465-477. doi:10.1177/0884217503255199

Ricciardelli, L. A., \& McCabe, M. P. (2001). Children's body image concerns and eating disturbance: A review of the literature. Clinical Psychology Review, 21(3), 325-344. doi:10.1016/S0272-7358(99)00051-3

Rodgers, R. F., Paxton, S. J., McLean, S. A., Campbell, K. J., Wertheim, E. H., Skouteris, H., \& Gibbons, K. (2013). Do maternal body dissatisfaction and dietary restraint predict weight gain in young pre-school children? A 1-year follow-up study. Appetite, 67, 3036. doi:10.1016/j.appet.2013.03.009

Shloim, N., Edelson, L. R., Martin, N., \& Hetherington, M. M. (2015). Parenting styles, feeding styles, feeding practices, and weight status in 4-12 year-old children: A systematic review of the literature. Frontiers in Psychology, 6. doi:10.3389/fpsyg.2015.01849

Stunkard, A. J., Sorensen, T, \& Schulsinger, F. (1983). Use of the Danish adoption register for the study of obesity and thinness. In S. Kety (Ed.), The genetics of neurological and psychiatric disorders (pp. 115-120). New York: Raven Press. 
Tan, C. C., \& Holub, S. C. (2011). Children's self-regulation in eating: Associations with inhibitory control and parents' feeding behavior. Journal of Pediatric Psychology, 36(3), 340-345. doi:10.1093/jpepsy/jsq089

Taylor, C., Wernimont, S., Northstone, K., \& Emmett, P. (2015). Picky/fussy eating in children: Review of definitions, assessment, prevalence and dietary intakes. Appetite, 95, 349-359. 10.1016/j.appet.2015.07.026

Thompson, J. K., Thompson, J. K., Altabe, M. N., \& Altabe, M. N. (1991). Psychometric qualities of the figure rating scale. International Journal of Eating Disorders, 10, 615619. doi:10.1002/1098-108X(199109)10:5<615::AID-EAT2260100514>3.0.CO;2-K

Tiggemann, M. (2004). Body image across the adult life span: Stability and change. Body Image, 1(1), 29-41. doi:10.1016/S1740-1445(03)00002-0

Tiggemann, M., \& Lowes, J. (2002). Predictors of maternal control over children's eating behaviour. Appetite, 39(1), 1-7. 10.1006/appe.2002.0487

Webber, L., Cooke, L., Hill, C., \& Wardle, J. (2010). Child adiposity and maternal feeding practices: A longitudinal analysis. American Journal of Clinical Nutrition, 92(6), 14231428. 10.3945/ajen.2010.30112

Wehrly, S. E., Bonilla, C., Perez, M., \& Liew, J. (2014). Controlling parental feeding practices and child body composition in ethnically and economically diverse preschool children. Appetite, 73, 163-171. doi:10.1016/j.appet.2013.11.009

Zimmer-Gembeck, M. J., \& Skinner, E. A. (2011). The development of coping across childhood and adolescence: An integrative review and critique of research. International Journal of Behavioral Development, 35(1), 1-17. doi:10.1177/0165025410384923 


\section{Table 1.}

$M$ s and $S D$ s for all variables, correlations (indicating stability) and paired samples $t$-tests (indicating continuity) between feeding practices

\begin{tabular}{|c|c|c|c|c|c|}
\hline & \multirow{2}{*}{$M$} & \multirow{2}{*}{$S D$} & \multirow{2}{*}{$\begin{array}{c}\text { Prospective } \\
r\end{array}$} & \multicolumn{2}{|c|}{ Paired samples } \\
\hline & & & & $t$ & $p$ \\
\hline 1. Body dissatisfaction ${ }^{\mathrm{T} 1}$ & 1.48 & 1.40 & & & \\
\hline 2. Concern about child weight ${ }^{\mathrm{T} 1}$ & 1.76 & 1.15 & & & \\
\hline 2. Pressure to eat ${ }^{\mathrm{T} 1}$ & 2.80 & 0.85 & & & \\
\hline 3. Pressure to eat ${ }^{\mathrm{T} 2}$ & 2.69 & 0.85 & $.76^{* * *}$ & 1.29 & .20 \\
\hline 4. Restriction health ${ }^{\mathrm{T} 1}$ & 2.92 & 0.85 & & & \\
\hline 5. Restriction health ${ }^{\mathrm{T} 2}$ & 2.69 & 0.98 & $.58 * * *$ & 1.89 & .07 \\
\hline 6. Restriction weight ${ }^{\mathrm{T} 1}$ & 1.90 & 0.71 & & & \\
\hline 7. Restriction weight ${ }^{\mathrm{T} 2}$ & 1.78 & 0.64 & $.40 * *$ & $-5.80 * * *$ & $<.001$ \\
\hline
\end{tabular}




\section{Table 2.}

Multiple Regression Analyses Predicting T2 Controlling Feeding Practices from T1 Body Dissatisfaction, Controlling Feeding Practices and Concern about Child Weight

\begin{tabular}{|c|c|c|c|}
\hline & $B$ & $S E(B)$ & $\beta$ \\
\hline & \multicolumn{3}{|c|}{ T2 Restriction for child weight } \\
\hline & \multicolumn{3}{|c|}{$R^{2}=.734, F(5,42)=23.18, p<.001}$. \\
\hline Parental body dissatisfaction & 0.09 & 0.04 & $.19 *$ \\
\hline Restriction for child health & 0.05 & 0.07 & .06 \\
\hline Restriction for child weight & 0.76 & 0.10 & $.83 * * *$ \\
\hline Pressure to eat & 0.01 & 0.06 & .01 \\
\hline \multirow[t]{3}{*}{ Concern about child weight } & -0.03 & 0.07 & -.06 \\
\hline & \multicolumn{3}{|c|}{ T2 Restriction for child health } \\
\hline & \multicolumn{3}{|c|}{$R^{2}=.385, F(5,42)=5.27, p=.001$} \\
\hline Parental body dissatisfaction & 0.09 & 0.09 & .13 \\
\hline Restriction for child health & 0.58 & 0.17 & $.50 * *$ \\
\hline Restriction for child weight & 0.21 & 0.23 & .15 \\
\hline Pressure to eat & 0.07 & 0.14 & .06 \\
\hline \multirow[t]{3}{*}{ Concern about child weight } & 0.03 & 0.16 & .03 \\
\hline & \multicolumn{3}{|c|}{ T2 Pressure to eat } \\
\hline & \multicolumn{3}{|c|}{$R^{2}=.591, F(5,42)=12.15, p<.001}$. \\
\hline Parental body dissatisfaction & 0.01 & 0.06 & .02 \\
\hline Restriction for child health & -0.04 & 0.12 & -.04 \\
\hline Restriction for child weight & 0.13 & 0.06 & .02 \\
\hline Pressure to eat & 0.77 & 0.10 & $.77 * * *$ \\
\hline Concern about child weight & -0.01 & 0.11 & -.02 \\
\hline
\end{tabular}

Note. All independent variables are T1, and dependent variables are T2.

$* p<.05, * * p<.01, * * * p<.001$. 